\title{
Interactive comment on "Predicting power outages caused by extratropical storms" by Roope Tervo et al.
}

\section{Roope Tervo et al.}

roope.tervo@fmi.fi

Received and published: 8 October 2020

We thank the reviewer for taking the time to read our paper and for giving us insightful, constructive, and extremely valuable comments and improvement suggestions. We have addressed all the comments as accurately and precisely as possible in the attached response document.

Please also note the supplement to this comment:

https://nhess.copernicus.org/preprints/nhess-2020-205/nhess-2020-205-AC1-

Printer-friendly version supplement.pdf 
2020-205, 2020.

NHESSD

Interactive

comment

Printer-friendly version

Discussion paper 